\title{
Comparison of Resampling Methods on Different Remote Sensing Images for Vietnam's Urban Classification
}

\author{
Pham Tuan Dung ${ }^{1}$, Man Duc Chuc ${ }^{1}$, Nguyen Thi Nhat Thanh ${ }^{1}$, Bui Quang Hung ${ }^{1}$, Doan Minh Chung ${ }^{2}$ \\ ${ }^{1}$ Center of Multidisciplinary Integrated Technology for Field Monitoring, University of Engineering and Technology, \\ Vietnam National University, Hanoi, Vietnam \\ 2 Space Technology Institute, Vietnam Academy of Science and Technology, Hanoi, Vietnam \\ Correspondence: Pham Tuan Dung, dungpt@fimo.edu.vn \\ Communication: received 15 December 2017, revised 15 June 2018, accepted 31 July 2018 \\ Online early access: 8 November 2018, Digital Object Identifier: 10.32913/rd-ict.vol2.no15.663 \\ The Area Editor coordinating the review of this article and deciding to accept it was Dr. Nguyen Viet Dung
}

\begin{abstract}
Remotely-sensed data for urban classification is very diverse in data type, acquisition time, and spatial resolution. Therefore, preprocessing is needed for input data, in which the spatial resolution must be changed by different resampling methods. However, data transformations during resampling have many effects on classification results. In this research, resampling methods were evaluated. The results showed that mean aggregation and bicubic interpolation methods performed better than the rest on a variety of data types. Besides, the highest overall accuracy and the F1 score for urban classification maps were $98.47 \%$ and $\mathbf{0 . 9 8 4 2}$, respectively.
\end{abstract}

Keywords: Urban classification, resampling, spatial resolution.

\section{INTRODUCTION}

In recent years, Vietnam has experienced an outbreak of urbanization due to its rapid economic growth. Urban development has been growing beyond any forecast although Vietnam's government has placed a strong emphasis on implementing both short and long-term policies to control this process. The Vietnam urbanization review by World Bank points out that Vietnam is in an intermediate step of urbanization (the current share of urban population is $30 \%$ with the growth rate of $3.4 \%$ per year) and an increasing economic transition toward industrial manufacturing [1]. In fact, urbanization plays an essential role in affecting environmental factors, such as terrestrial ecosystems and climate change [2]. Besides, there is a tightened relationship between urban expansion and population growth as well as green areas reduction in Vietnam [3]. Therefore, it is needed to develop a practical urban classification algorithm for building Vietnam's urban maps, which help decision makers in monitoring and planning Vietnam's infrastructure development.

In Vietnam, there are several studies in urban classification methodologies and evaluating effects of urbanization on the environment. The subjects of such studies, for examples, include sustainable urbanization in Vietnam [4], relationships between surface temperature and land cover in Ho Chi Minh city using remote sensing data [5], land use change in Da Nang city [6], optimizing spatial resolution of remote sensing data for urban detection [7], the relation between city planning and urban growth using remote sensing and spatial metrics [8], and assessing the impact of urbanization on urban climate by using remote sensing images [9].

Numerous studies have been conducted for urban mapping at a global scale using both coarse and fine-resolution satellite data. GLCNMO is one of the best popular global urban mapping products. It has three versions at 500meter spatial resolution including GLCNMO 2003 (version 1) [10], GLCNMO 2008 (version 2) [11], and GLCNMO 2013 (version 3) [12].

In our previous research [3], we used the GLCNMO v2 method to build Vietnam's urban maps at 500-meter spatial resolution. The method is divided into two main steps including a preprocessing step and a processing step. In the preprocessing step, we applied the best combination of resampling methods for input data, which were the maximum aggregation method for MODIS-NDVI data and the nearest-neighbor interpolation method for night-time light data and impervious surface area data. The processing step was based on a decision tree algorithm. Precision, recall, and F1 measures were used to assess the accuracy of 
the output maps. Results showed that the improved method obtained increases of $13 \%$ in precision and $10 \%$ in $\mathrm{F} 1$ score compared to the global GLCNMO v2 method.

Because GLCNMO v2 uses several input datasets with different spatial resolutions, the transformation of all remote sensing data to a common spatial resolution is an important process of this study in particular and the studies of land cover classification in general. The spatial resolution affects the classification accuracy of remote sensing images due to two factors [13]. The first is the change in the number of pixels affected at the boundary between classes and the second is the change in the spectral variations within classes. As the spatial resolution of the remote sensing image increases, the number of mixed pixels decreases, which helps achieve better classification accuracy. However, the spectral variation within classes will become more complex, which leads to reducing the accuracy of the classification process. In fact, the interaction of these two factors represents the two faces of resampling methods.

In fact, there are many works focusing on comparing the effects of resampling methods for remote sensing data. Studley and Weber compared different image resampling techniques implemented by various software vendors [14]. Bian and Butler figured out effects of three spatial data aggregation methods on statistical and spatial properties [15]. Xiuling et al. proposed an index to evaluate various aggregation methods by comparing aggregated classification data with control data of the same scale [16]. Patel and Mistree reviewed different image interpolation methods in general [17]. Titus and Geroge compared different interpolation techniques based on remotely-sensed images [18].

The objective of this research is to compare resampling techniques on discrete (DMSP-OLS, EstISA, and Worldpop), continuous (MODIS, MOD13Q1, and NDVI), and categorical (MOD44W) datasets of remote sensing images and analyze their effects on Vietnam's urban classification. Specifically, the following research statements are investigated: (i) different resampling methods may have different results in accuracy of algorithms for urban classification, and (ii) different resampling methods may need different appropriate thresholds for input data.

From these research statements, the goal of the paper is to present two contributions. First, while other works typically keep the same input data and change the algorithms to find out the best algorithm, our approach is to focus on the resampling step, in which we hold the algorithm and change the resampling method to find out the best combination of resampling methods for the input data. Second, thresholds of input data are calculated automatically based on the training data.
TABLE I

INPUT DATA OF THIS RESEARCH

\begin{tabular}{llll}
\hline Abbreviation & Data Description & $\begin{array}{l}\text { Spatial } \\
\text { Resolution }\end{array}$ & Time \\
\hline Worldpop & $\begin{array}{l}\text { Population density } \\
\text { Stable night-time light }\end{array}$ & $\begin{array}{l}100 \mathrm{~m} \\
1 \mathrm{~km}\end{array}$ & 2015 \\
MODIS/Terra & & 2013 \\
MOD13Q1 & $\begin{array}{l}\text { Vegetation Indices } \\
\text { 16-Day L3 Global }\end{array}$ & $250 \mathrm{~m}$ & 2015 \\
EstISA & $\begin{array}{l}\text { Impervious surface } \\
\text { area }\end{array}$ & $1 \mathrm{~km}$ & 2010 \\
MOD44W & $\begin{array}{l}\text { MODIS inland } \\
\text { water mask }\end{array}$ & $250 \mathrm{~m}$ & N/A \\
\hline
\end{tabular}

\section{Study Area ANd Data}

\section{Study Area}

Vietnam is a country located on the Indochinese peninsula in the Southeast Asia region. Vietnam has about $4,550 \mathrm{~km}$ of land border shared with China to the north, and Laos and Cambodia to the west; and to the east is the South China Sea (the East Sea of Vietnam). The S-shaped country has a north-to-south distance of $1,650 \mathrm{~km}$ from $8^{\circ} 27^{\prime}$ North to $23^{\circ} 23^{\prime}$ North and is about 500-kilometer wide at the widest part and 50-kilometer wide at the narrowest part [2].

Vietnam has a diverse terrain that reflects the history of geological changes amid a tropical monsoon climate. Three-quarters of Vietnam is mountainous or hilly with the majority of mainland areas is less than $500 \mathrm{~m}$ in altitude, and areas above $2000 \mathrm{~m}$ in altitude account for only one percent. The highest mountain ranges lie in the west and northwest of the country. Its deltas occupy only one-fourth of the mainland and are separated into several areas. There are two large, fertile deltas: the Red River Delta (Red River Basin, 16,700 $\mathrm{km}^{2}$ ) and the Southern Delta (Mekong River Basin, 40,000 $\mathrm{km}^{2}$ ). Located between the two large deltas is a series of small deltas along the central coast with a total area of $15,000 \mathrm{~km}^{2}$. The delta areas are the focal points of urbanization (accounting for more than $90 \%$ of regional cities) [2].

\section{Data}

The input data used in this research is described in Table I.

\section{1) High-resolution population distribution data:}

Vietnam's 2015 population distribution data was already generated at 100-meter spatial resolution and projected to the WGS 84 geographic coordinate system. The data is freely downloaded from website http://www.worldpop. org.uk [19]. 


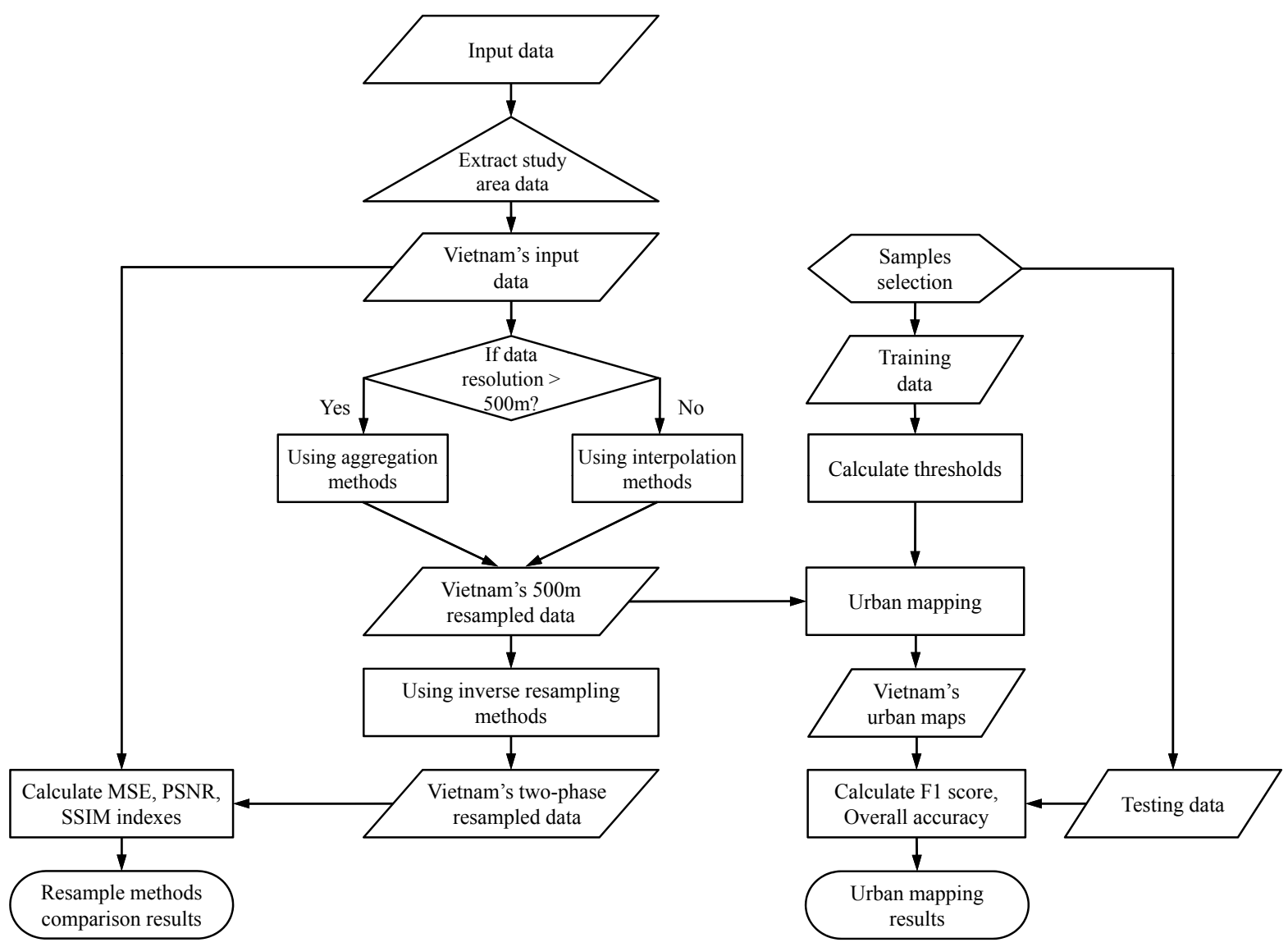

Figure 1. General flowchart of the research.

\section{2) Night-time light data for Vietnam:}

The Version 4 Defense Meteorological Satellite Program - Operational Linescan System (DMSP-OLS) nighttime light imagery is available at http://ngdc.noaa.gov/ eog/dmsp/. This product has 500-meter spatial resolution, and the digital number values range from 0 to 63 .

Stable night-time light data in 2013 of DMSP-OLS (F18 satellite) composite product was used in this study [20].

\section{3) MODIS-NDVI data:}

MODIS/Terra Vegetation Indices 16-Day L3 Global SIN Grid 250-meter spatial resolution images (MOD13Q1) were downloaded from the NASA Land Processes Distributed Active Archive Center (http://earthexplorer.usgs.gov/). A Maximum Value Composition (MVC) was then applied to all 23 composite images for 2015 data [21].

4) Estimating the density of constructed Impervious Surface Area (EstISA) data:

The global impervious surface area density grid was produced on a 30 arc-second grid. It was then converted to an 1-kilometer grid in a WGS 84 projection. Its values range from 1 to 100 . The global grid of ISA at the resolution of 1-kilometer is freely available at http://www.ngdc.noaa.gov/dmsp [22].

5) Waterbody data:

The MODIS land-water mask at 250-meter spatial resolution (MOD44W) is produced by using the Shuttle Radar Topography Mission Water Body Data (SWBD) in combination with MODIS 250-meter data to create a complete global map of surface water. MOD44W data was downloaded at https://lpdaac.usgs.gov/data_access [23].

\section{Methodology}

The general flowchart of this research is described in Figure 1. The research is divided into two main parts. The first one is a comparison of resampling methods on different remote sensing images. The second one is to evaluate the effects of resampling methods on Vietnam's urban classification.

\section{Extracting Study Area Data}

NDVI data was extracted from MODIS MOD13Q1 data which consists of 23 periods of the 16-day composite in 2015. NDVI data of the maximum 23 periods was generated. 
In this preparation step, all global input data was clipped by the Vietnam's administrative boundaries, resulting in Vietnam's input data.

\section{Comparison of Resampling Methods}

\section{1) Resampling methods:}

a) Aggregation methods: Image aggregation of remote sensing data is widely used in various studies, including land use or land cover, natural resource management, etc. The aggregation process divides the input spatial data into a smaller number of data units having a same spatial extent, and the representing value of each aggregated data unit is a correlating value in coarser spatial resolution data [24]. In fact, spatial input images at finer resolutions must be aggregated to represent the spatial characteristics at corresponding coarse scales.

Two techniques are used for aggregating fine-resolution remote sensing data, including categorical aggregation and numerical aggregation. The former picks the class labels of coarse-resolution pixels based on the classes in the related fine-resolution pixels of the original data. The latter determines the coarse-resolution pixel values by a function of the associated fine-resolution pixels. In short, for categorical aggregation, data is classified and then aggregated whereas, for numerical aggregation, data is aggregated and then classified. Both of these approaches alter the spatial resolution of remote sensing images in different ways. There are several categorical aggregation methods, for instances, majority rule-based, random rule-based, and point-centered distance-weighted moving window [25]. The numerical aggregation methods use sum aggregation, central pixel, mean, median, minimum, maximum, or random value of a data unit, etc.

b) Interpolation methods: Image interpolation is an important step in image processing aimed at increasing the spatial resolution of remote sensing data. In fact, high-resolution remote sensing data is often expensive. Therefore, interpolation methods are used to enhance the coarser spatial resolution data (which is usually provided for free or at a lower cost) to improve the image quality. Besides, many types of remote sensing research have to deal with the problems of specific resolution data availability. The available multi-source multi-resolution input images rarely fit the needed spatial resolution for data processing. Therefore, a spatial transformation is required to rescale the data before integration [14].

Interpolation methods estimate the continuous value of a pixel by a function of the values of related pixels. An interpolated pixel has a spatial relationship with neighboring pixels, and interpolated images will be smoother than the original ones.
This paper uses some common interpolation techniques such as nearest-neighbor, bilinear, and bicubic interpolations [14].

\section{2) Processing step of resampling:}

Each of the five input datasets was resampled using several methods. Three interpolation methods including nearest-neighbor, bilinear, and bicubic interpolation were used to resample DMSP-OLS and EstISA data. Four aggregation methods respectively using mean, median, minimum, and maximum pixels were used to resample MOD13Q1 NDVI data.

Because Worldpop and MOD44W datasets have different characteristics, the sum aggregation method was applied to Worldpop data, and the majority aggregation method was used to resample MOD44W data.

After the first resampling step, resampled data were used as input data for the correlative threshold-based urban classification algorithm.

Two phases of the processing step of resampling were carried out as in Figure 2. First, EstISA, MOD13Q1, and DMSP-OLS data resampled at phase 1 was resampled once again in phase 2 with the inversion of the method used in the first phase. Second, the transformed data having the same spatial resolution with the original data was compared with Vietnam's input data to evaluate the variability after resampling.

\section{3) Performance metrics:}

In this paper, the reconstructed images were compared to the original images. Mean square error, peak signal-to-noise ratio, and structural similarity index were used to measure the effects of resampling methods on the spatial data.

The mean squared error (MSE) is one of the most important criteria used to evaluate the performance of a predictor or an estimator. The MSE is also useful in reflecting the concepts of bias, precision, and accuracy in statistical estimation. To estimate the MSE, you need a target of estimation or prediction and a predictor or estimator that is a function of the data [26].

The peak signal-to-noise ratio (PSNR) is a ratio between the maximum possible power of a signal and the power of corrupting noise that affects the fidelity of its representation. The PSNR is usually expressed in the decibel (dB) scale. PSNR is a rough estimation of human perception of reconstruction quality. A higher PSNR indicates that the reconstruction is of higher quality in image compression [27].

The structural similarity index (SSIM) is a method to measure the similarity between two remote sensing images. The SSIM can be viewed as a quality measure of a source image compared to a destination image regarded as of perfect quality [28]. 


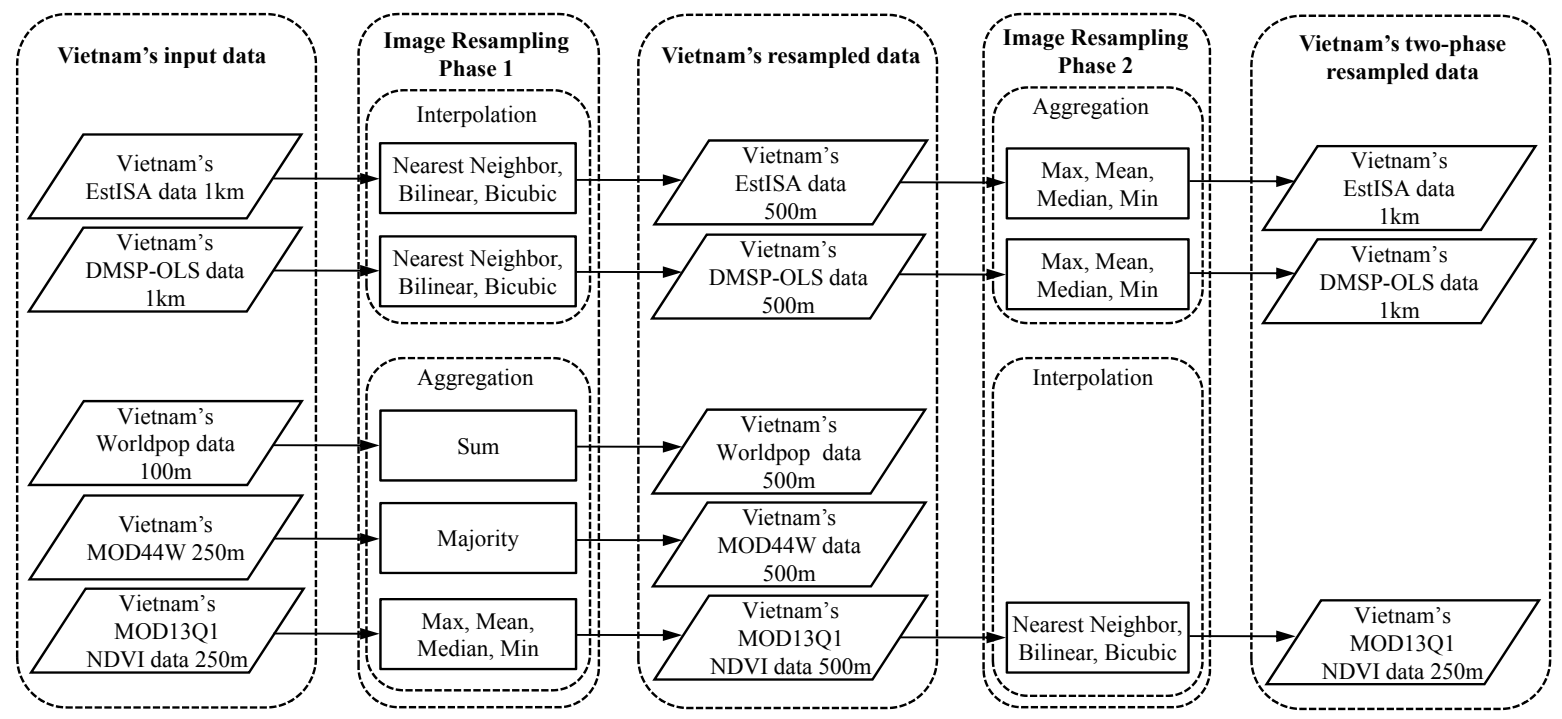

Figure 2. Flowchart of the processing step during resampling.

TABLE II

THRESHOLD VALUES OF RESAMPLED DATA

\begin{tabular}{|c|c|c|c|}
\hline Input data & $\begin{array}{l}\text { Resampling } \\
\text { method }\end{array}$ & Threshold & $\begin{array}{l}\text { Training } \\
\text { accuracy }(\%)\end{array}$ \\
\hline \multirow{3}{*}{ EstISA } & $\begin{array}{l}\text { NEAREST } \\
\text { NEIGHBOUR }\end{array}$ & 3 & 97.55 \\
\hline & BILINEAR & 3 & 97.63 \\
\hline & BICUBIC & 3 & 97.63 \\
\hline \multirow{4}{*}{$\begin{array}{l}\text { NDVI } \\
\text { MOD13Q1 }\end{array}$} & MAXIMUM & 0.68 & 93.28 \\
\hline & MEAN & 0.62 & 94.07 \\
\hline & MEDIAN & 0.57 & 93.99 \\
\hline & MINIMUM & 0.56 & 93.91 \\
\hline \multirow{3}{*}{$\begin{array}{l}\text { DMSP_ } \\
\text { OLS }\end{array}$} & $\begin{array}{l}\text { NEAREST } \\
\text { NEIGHBOUR }\end{array}$ & 22 & 98.02 \\
\hline & BILINEAR & 22 & 98.10 \\
\hline & BICUBIC & 22 & 98.02 \\
\hline Worldpop & SUM & 400 & 98.66 \\
\hline MOD44W & MAJORITY & 1 & - \\
\hline
\end{tabular}

\section{Vietnam's Urban Classification}

\section{1) Sample selection:}

100 sampled polygons containing the urban areas throughout Vietnam were selected. After that, 500-meter spatial resolution points were calculated based on these polygons. Points of non-urban classes (for instances, forest, bare land, water, etc., which are based on GLCNMO v3' classes) were taken randomly throughout Vietnam's territory by stratified sampling. These points were rechecked by comparison with high-resolution data such as Google Earth and Landsat ETM+, including 618 urban points (Figure 3(a)) and 1039 non-urban points (Figure 3(b)). These points were randomly split into two sets, a training set including 425 urban points and 839 non-urban points (Figure 3(c)) and a testing set containing 193 urban points and 200 non-urban points (Figure 3(d)).

According to the training set, appropriate thresholds were chosen automatically to separate urban and nonurban points into two distinct parts. Firstly, histograms of resampled EstISA, DMSP-OLS, and MOD13Q1 NDVI data were computed from the training set, as shown in Figures 4, 5 , and 6, respectively. Secondly, the appropriate threshold for each dataset is determined from the corresponding histogram by the following function:

thresholding (urban_histogram, non_urban_histogram, total_non_urban_points)

1: for $i$ in range(data_size_value)

2: $\quad$ sum_urban = sum_urban + urban_histogram $[i]$;

3: $\quad$ sum_non_urban = sum_non_urban + non_urban_histogram $[i]$;

4: $\quad$ oa $=$ sum_urban $+($ total_non_urban_points sum_non_urban);

5: $\quad$ if oa $>$ training_accuracy

6: $\quad$ training_accuracy $=$ oa

7: $\quad$ threshold $=i$

8: $\quad$ end if

9: end for

10: return threshold, training_accuracy

The steps of the for-loop depend on the input data, they are 1, 1, and 0.01 for EstISA, DMSP-OLS, and MOD13Q1 NDVI datasets, respectively. The sizes of EstISA, DMSPOLS, and MOD13Q1 NDVI datasets are 100, 63, and 1, respectively. In this case, the number of non-urban points is 839. The training accuracy shows how good the thresholds are in separating the training data into two distinct parts. The best thresholds and corresponding training accuracy values are listed in Table II. 


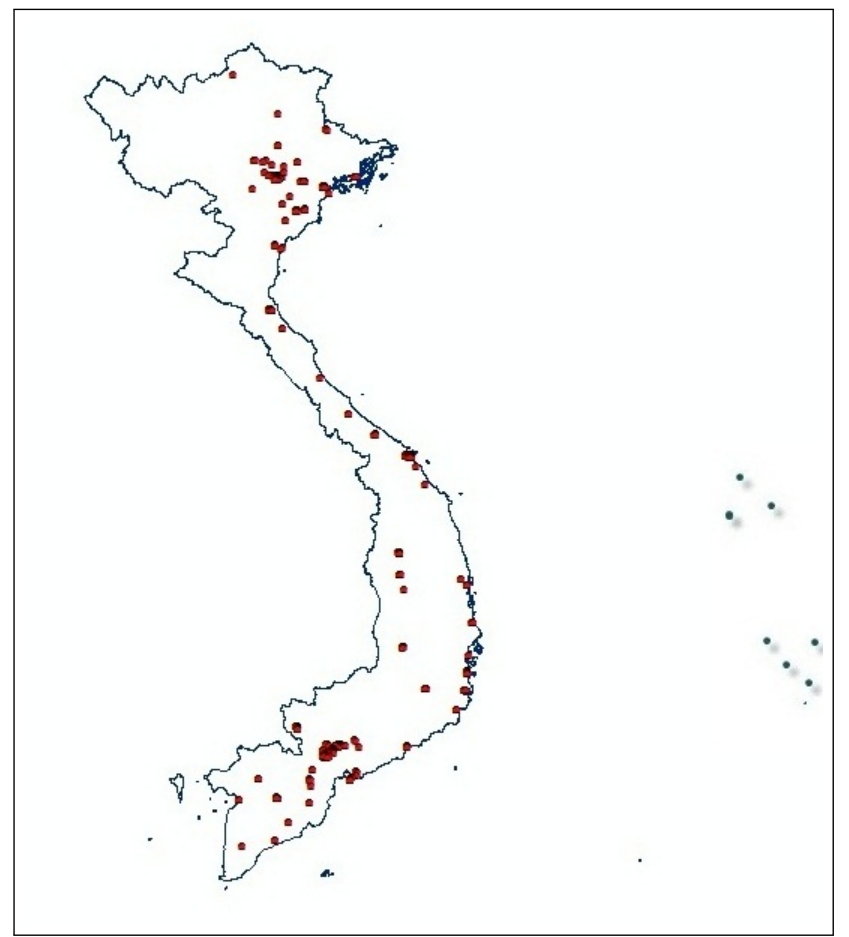

(a) 618 urban points

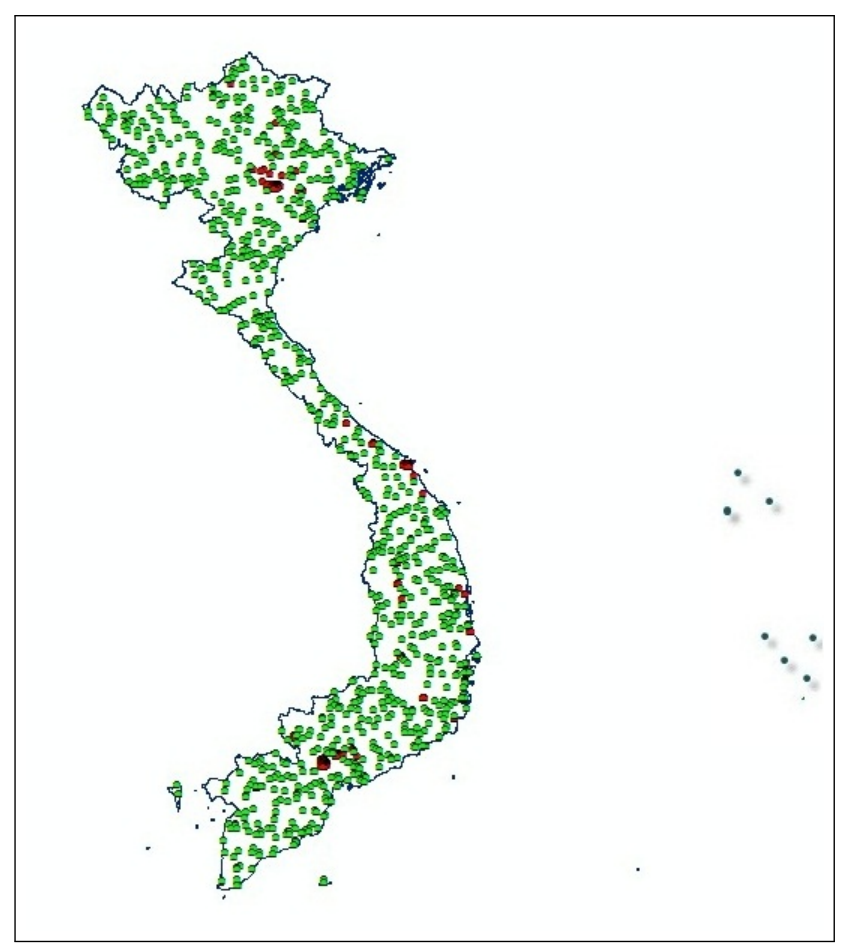

(c) Training set: 425 urban points and 839 non-urban points

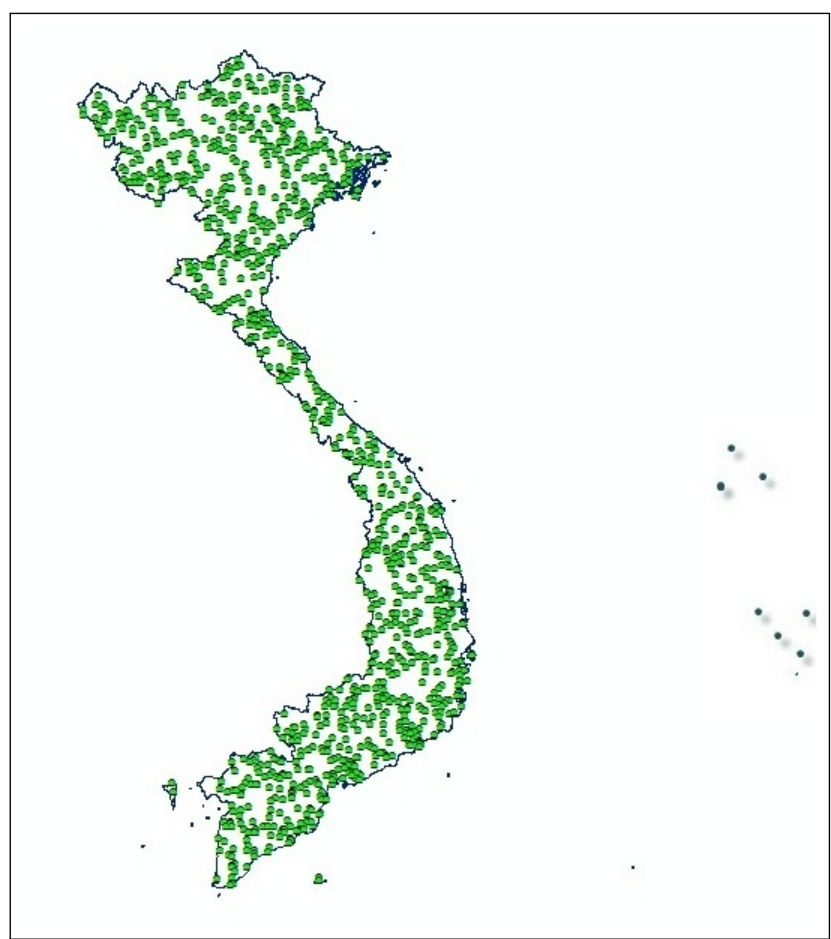

(b) 1039 non-urban points

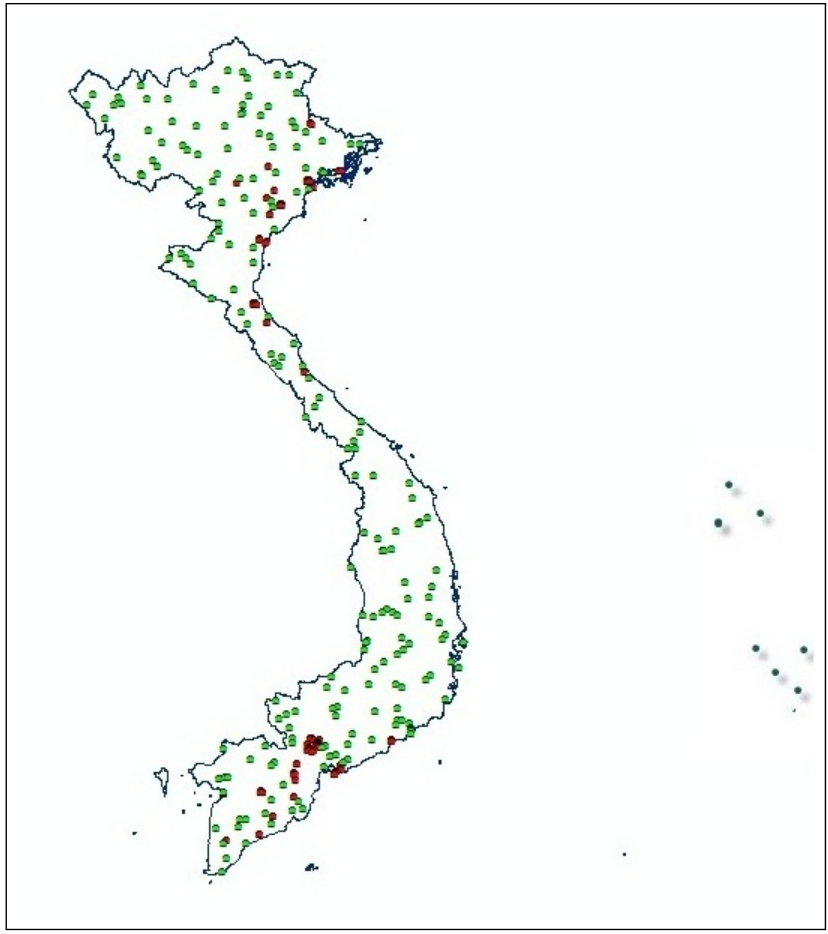

(d) Testing set: 193 urban points and 200 non-urban points

Figure 3. Sample selection. 


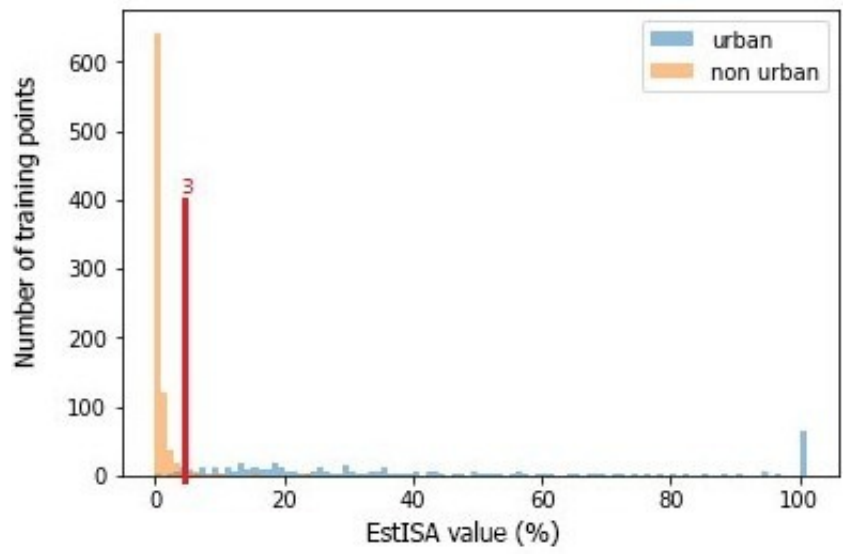

(a) Nearest-neighbor method

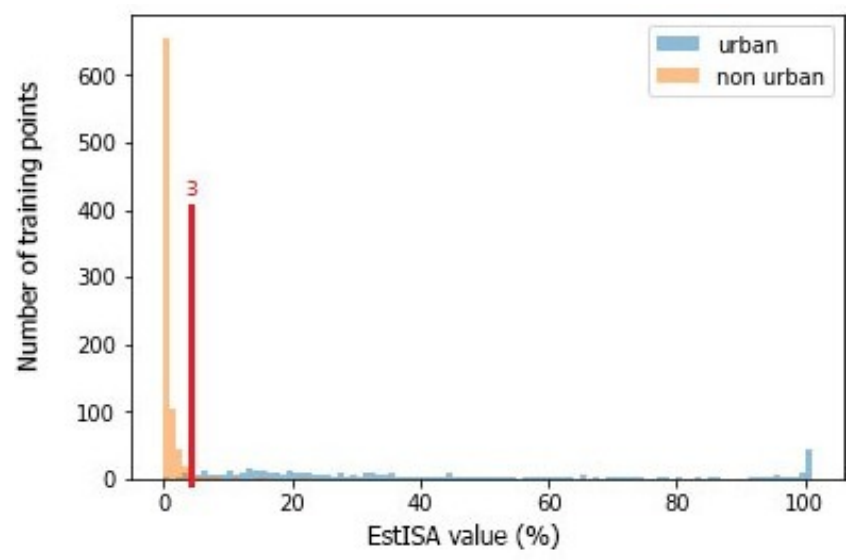

(b) Bilinear method

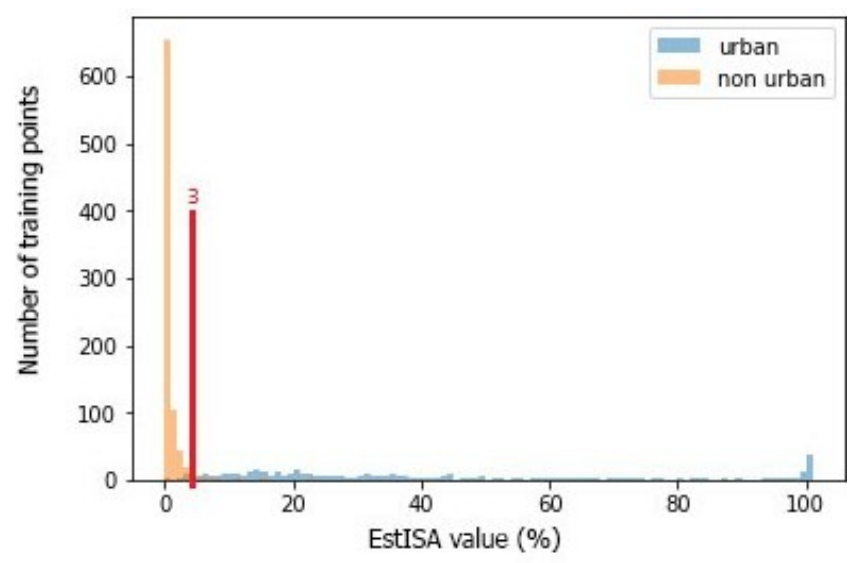

(c) Bicubic method

Figure 4. Histograms of resampled EstISA data.

2) Urban classification method:

The classification method was proposed in the GLCNMO v3 method [12]. It is described in Figure 7. The method was modified to adapt to Vietnam's data. For the original GLCNMO v3 method, the population density dataset is the LandScan 2012, however, its resolution (1-kilometer) is very coarse. Therefore, we used high-

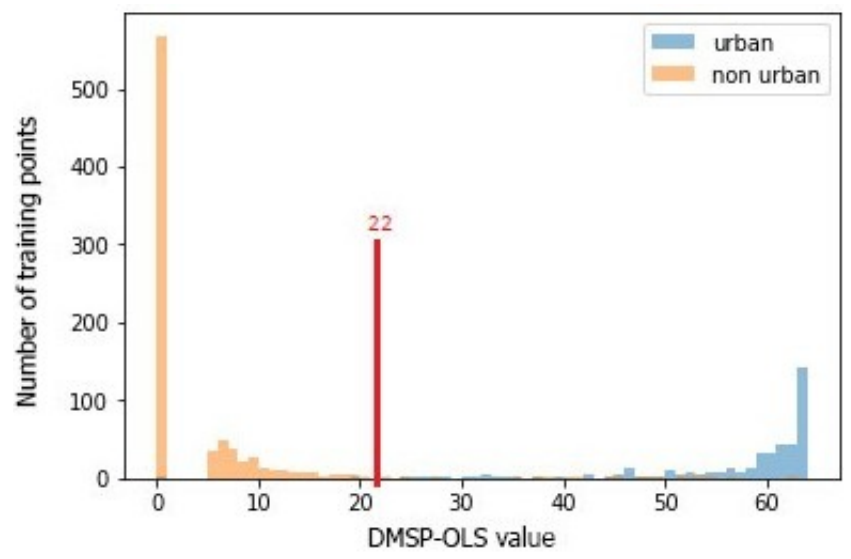

(a) Nearest-neighbor method

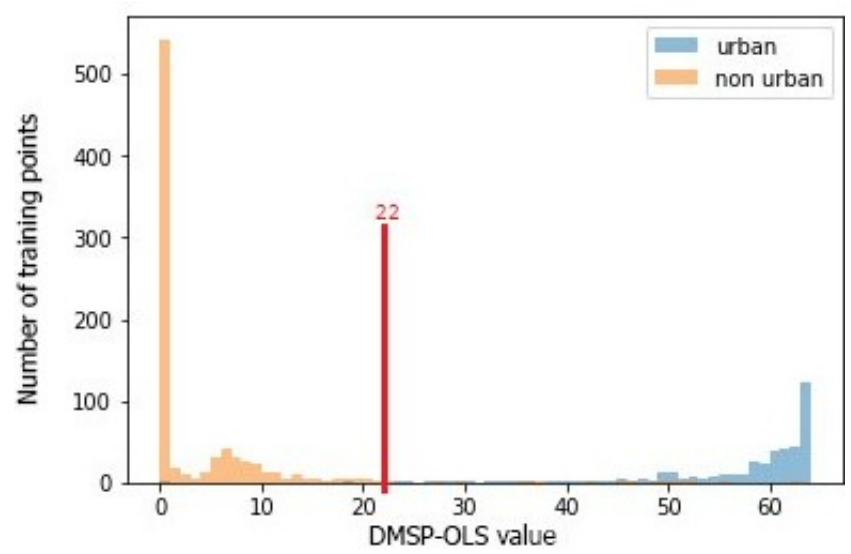

(b) Bilinear method

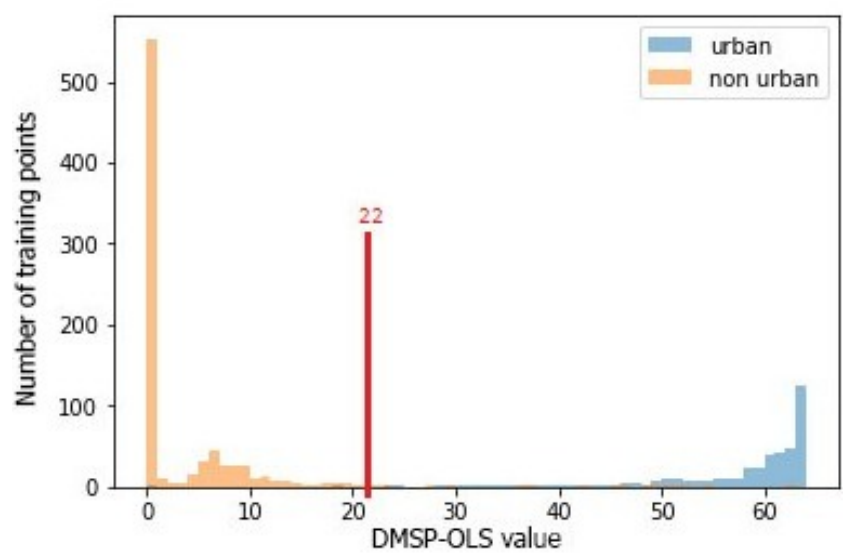

(c) Bicubic method

Figure 5. Histograms of resampled DMSP-OLS data.

resolution data (Worldpop, 100-meter) as an alternative.

The candidate maps were produced from the population data. The resulted maps were calculated by excluding less night-time light, less-impervious surface, greener, and water areas from potential urban areas based on thresholds which are shown in Table II. 


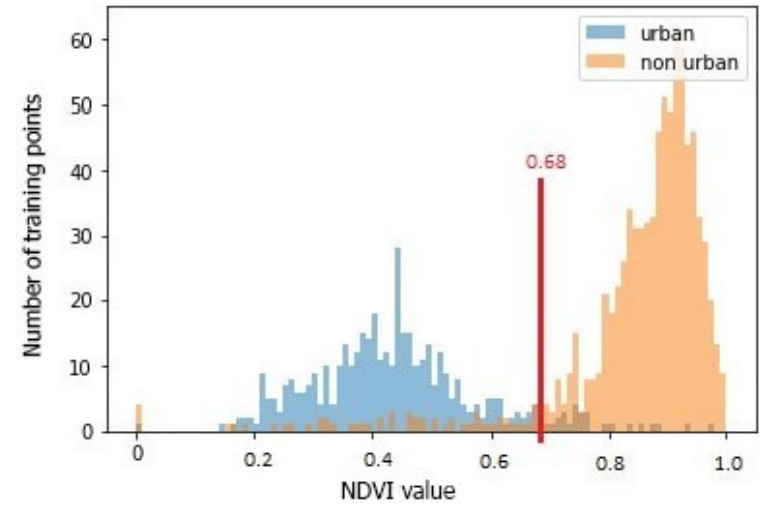

(a) Maximum aggregation method

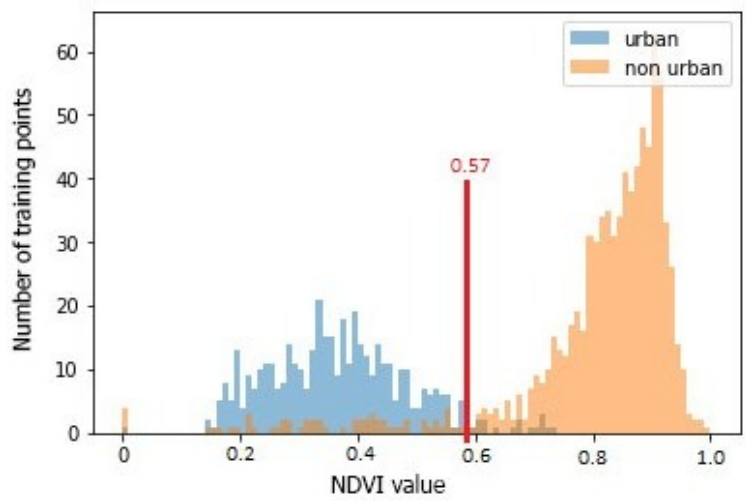

(c) Median aggregation method

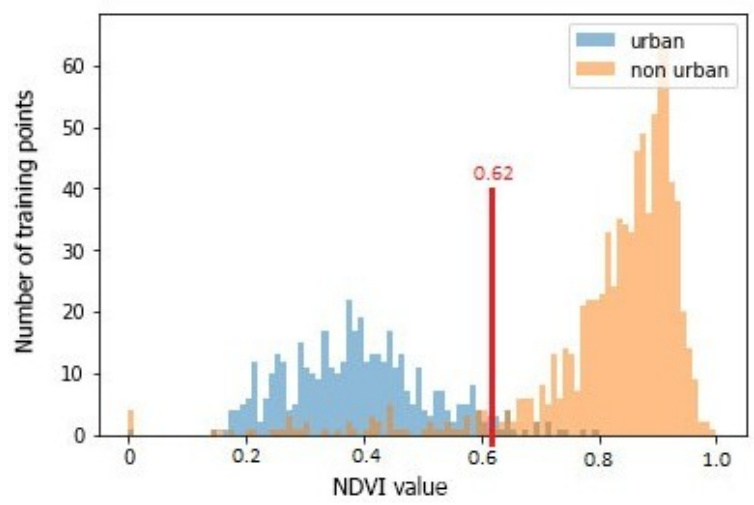

(b) Mean aggregation method

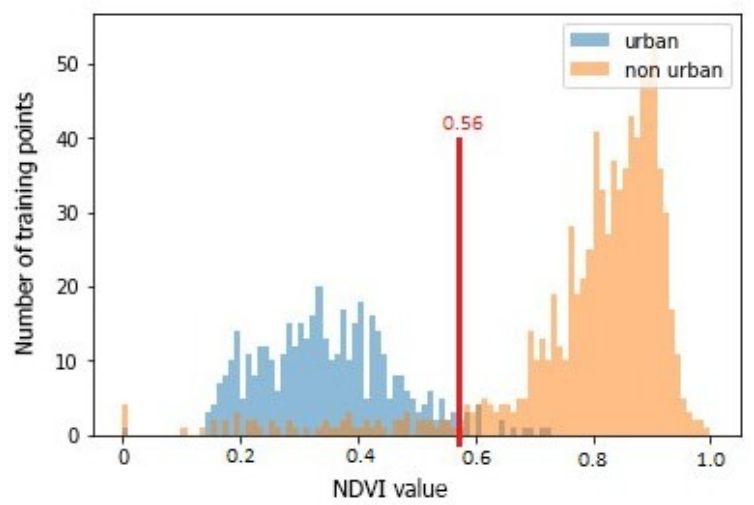

(d) Minimum aggregation method

Figure 6. Histograms of MOD13Q1 NDVI's resampled data.
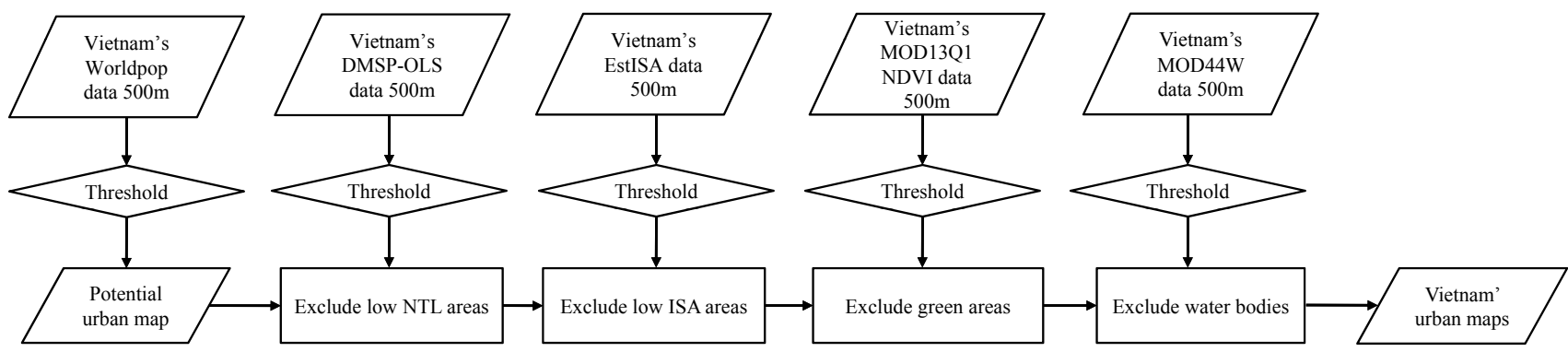

Figure 7. Flowchart of urban mapping.

\section{3) Evaluation of urban classification method:}

To evaluate the accuracy of the resulted map, we calculated precision, recall, F1 score, and the overall accuracy based on the test set selected in the sample seclection step.

The accuracy values of 36 combinations of resampled data were compared to find out the best result.

\section{RESUlts AND Discussion}

\section{Comparison of Resampling Methods}

Five datasets were resampled to a same spatial resolution (500-meter) in phase 1 of the resampling step. These data were used as the input data for the urban classification algorithm.

Because Worldpop and MOD44W datasets were transformed by only one corresponding resampling method, a comparison is not needed for these methods.

The output data after the two-phase resampling process on EstISA, DMSP-OLS, and MOD13Q1 NDVI data was compared with Vietnam's input data using MSE, PSNR, and SSIM indexes. The lower MSE is better and vice versa. The higher PSNR and SSIM are better and vice versa. The results are shown in Figures 9, 10, and 11. 


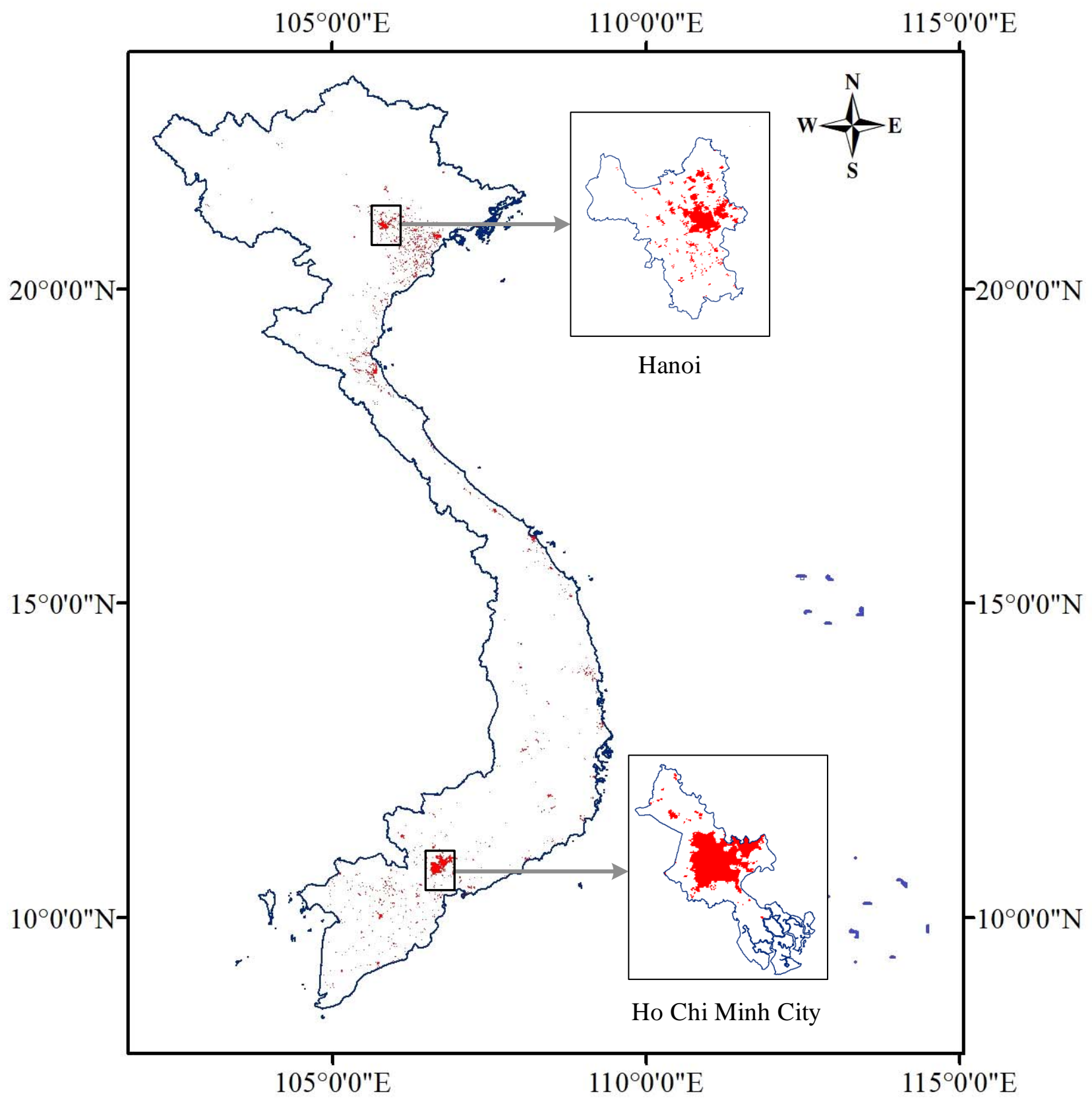

Figure 8. Combined Vietnam's urban map using sum aggregation for Worldpop data, nearest-neighbor interpolation for DMSP-OLS data, bilinear interpolation for EstISA data, mean aggregation for MOD13Q1 NDVI data, and majority aggregation for MOD44W data.
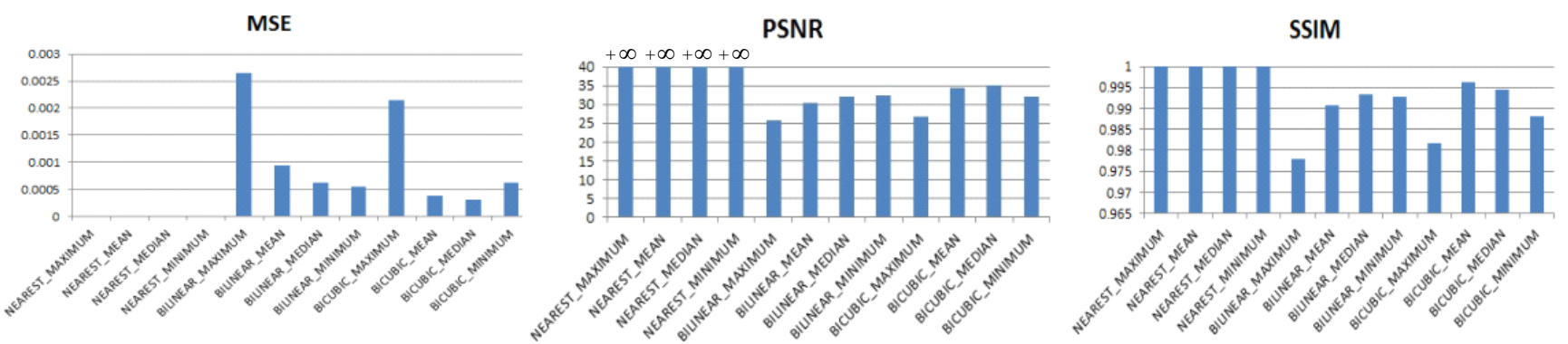

Figure 9. Performance metrics of two-phase resampling methods on EstISA data. 

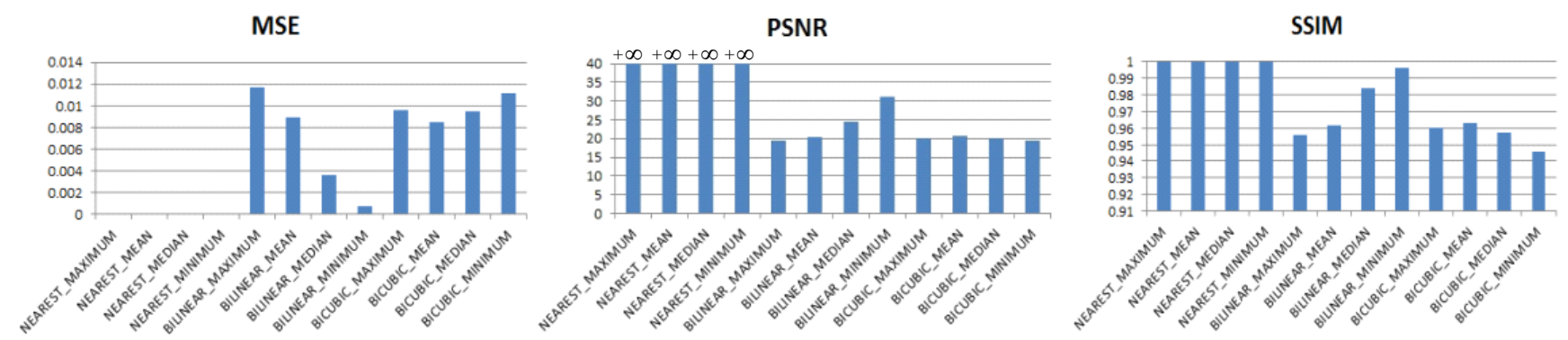

Figure 10. Performance metrics of two-phase resampling methods on DMSP-OLS data.
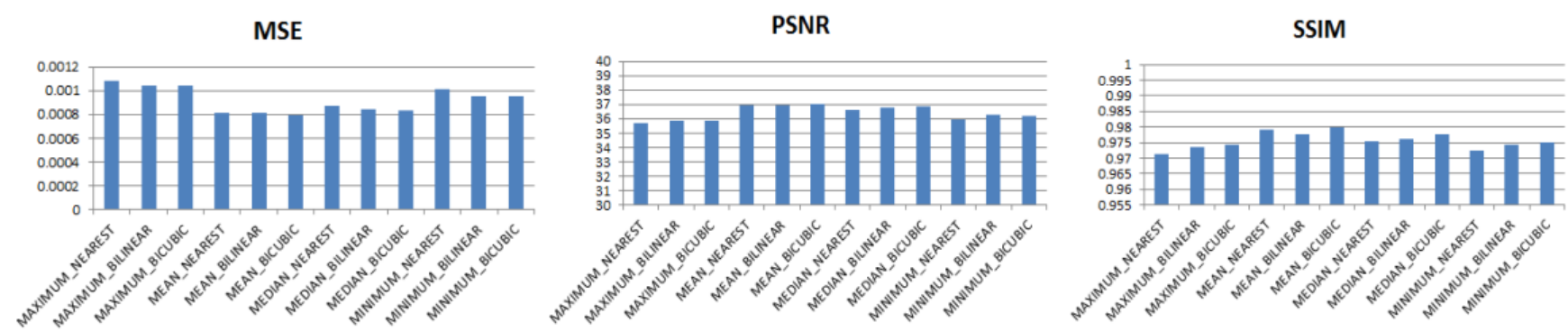

Figure 11. Performance metrics of two-phase resampling methods on MOD13Q1 NDVI data.

For EstISA data, as shown in Figure 9, the nearestneighbor interpolation combined with other aggregation methods produced the best results (with the lowest MSE and the highest PSNR and SSIM indexes of $0,+\infty$, and 1 , respectively), while the bilinear-maximum combination produced the worst results (with the highest MSE and the lowest PSNR and SSIM indexes of 0.0026, 25.7724, and 0.9779, respectively).

For DMSP-OLS data, as shown in Figure 10, the nearestneighbor interpolation combined with other aggregation methods yielded the best results (with the lowest MSE and the highest PSNR and SSIM indexes of $0,+\infty$, and 1 , respectively), while the bicubic-minimum combination produced the worst results (with the highest MSE and the lowest PSNR and SSIM indexes of 0.0112, 19.5249, and 0.9455 , respectively).

For MOD13Q1 data, as shown in Figure 11, the mean-bicubic combination produced the best results (with the lowest MSE and the highest PSNR and SSIM indexes of $0.0008,37.0509$, and 0.98 , respectively), while the maximum-nearest-neighbor combination produced the worst results (with the highest MSE and the lowest PSNR and SSIM indexes of $0.0011,35.6711$, and 0.9715 , respectively).

\section{Impacts of Resampling Methods on Vietnam's Urban Classification}

After applying urban classification algorithm based on thresholds to combine data taken from resampling, 36 corresponding urban maps were produced. For example, Vietnam's urban map, with the combination of sum aggregation for Worldpop data, nearest-neighbor interpolation for DMSP-OLS data, bilinear interpolation for EstISA data, mean aggregation for MOD13Q1 NDVI data, and majority aggregation for MOD44W data, is showed in Figure 8. Vietnam's urban area is $1955 \mathrm{~km}^{2}$, and its two largest cities, Hanoi and Ho Chi Minh city, are delineated urban areas of $276.25 \mathrm{~km}^{2}$ and $420 \mathrm{~km}^{2}$, respectively.

The testing set was used to evaluate the overall accuracy, and obtained results are shown in Table III. Because the data used in this research had coarse spatial resolutions, and the number of testing points is quite small, the overall accuracies of some combinations are equal. According to the results, the highest overall accuracy and F1 score are $98.47 \%$ and 0.9842 , respectively, with six combinations of input data. For example, one of the best results is the combination of sum aggregation for Worldpop data, bilinear interpolation for DMSP-OLS data, bicubic interpolation for EstISA data, mean aggregation for MOD13Q1 NDVI data, and majority aggregation for MOD44W data. This best combination shows that the results are mainly affected by the mean aggregation method of MOD13Q1 NDVI data.

\section{Conclusion}

Resampling methods have a significant impact on Vietnam's urban classification based on remote sensing data. What is the most appropriate resampling method depends on the data type (discrete, continuous, or categorical data). 
TABLE III

EFFECTS OF RESAMPLING METHODS ON VIETNAM'S URBAN CLASSIFICATION

\begin{tabular}{|c|c|c|c|c|}
\hline DMSP-OLS & EstISA & MOD13Q1 NDVI & Overall accuracy $(\%)$ & F1 score \\
\hline NEAREST NEIGHBOR & NEAREST NEIGHBOR & MAXIMUM & 96.95 & 0.9679 \\
\hline NEAREST NEIGHBOR & NEAREST NEIGHBOR & MEAN & 97.96 & 0.9788 \\
\hline NEAREST NEIGHBOR & NEAREST NEIGHBOR & MEDIAN & 97.20 & 0.9707 \\
\hline NEAREST NEIGHBOR & NEAREST NEIGHBOR & MINIMUM & 97.71 & 0.9761 \\
\hline NEAREST NEIGHBOR & BILINEAR & MAXIMUM & 97.46 & 0.9734 \\
\hline NEAREST NEIGHBOR & BILINEAR & MEAN & 98.47 & 0.9842 \\
\hline NEAREST NEIGHBOR & BILINEAR & MEDIAN & 97.71 & 0.9761 \\
\hline NEAREST NEIGHBOR & BILINEAR & MINIMUM & 98.22 & 0.9815 \\
\hline NEAREST NEIGHBOR & BICUBIC & MAXIMUM & 97.46 & 0.9734 \\
\hline NEAREST NEIGHBOR & BICUBIC & MEAN & 98.47 & 0.9842 \\
\hline NEAREST NEIGHBOR & BICUBIC & MEDIAN & 97.71 & 0.9761 \\
\hline NEAREST NEIGHBOR & BICUBIC & MINIMUM & 98.22 & 0.9815 \\
\hline BILINEAR & NEAREST NEIGHBOR & MAXIMUM & 96.95 & 0.9679 \\
\hline BILINEAR & NEAREST NEIGHBOR & MEAN & 97.96 & 0.9788 \\
\hline BILINEAR & NEAREST NEIGHBOR & MEDIAN & 97.20 & 0.9707 \\
\hline BILINEAR & NEAREST NEIGHBOR & MINIMUM & 97.71 & 0.9761 \\
\hline BILINEAR & BILINEAR & MAXIMUM & 97.46 & 0.9734 \\
\hline BILINEAR & BILINEAR & MEAN & $\mathbf{9 8 . 4 7}$ & 0.9842 \\
\hline BILINEAR & BILINEAR & MEDIAN & 97.71 & 0.9761 \\
\hline BILINEAR & BILINEAR & MINIMUM & 98.22 & 0.9815 \\
\hline BILINEAR & BICUBIC & MAXIMUM & 97.46 & 0.9734 \\
\hline BILINEAR & BICUBIC & MEAN & $\mathbf{9 8 . 4 7}$ & 0.9842 \\
\hline BILINEAR & BICUBIC & MEDIAN & 97.71 & 0.9761 \\
\hline BILINEAR & BICUBIC & MINIMUM & 98.22 & 0.9815 \\
\hline BICUBIC & NEAREST NEIGHBOR & MAXIMUM & 96.95 & 0.9679 \\
\hline BICUBIC & NEAREST NEIGHBOR & MEAN & 97.96 & 0.9788 \\
\hline BICUBIC & NEAREST NEIGHBOR & MEDIAN & 97.20 & 0.9707 \\
\hline BICUBIC & NEAREST NEIGHBOR & MINIMUM & 97.71 & 0.9761 \\
\hline BICUBIC & BILINEAR & MAXIMUM & 97.46 & 0.9734 \\
\hline BICUBIC & BILINEAR & MEAN & 98.47 & 0.9842 \\
\hline BICUBIC & BILINEAR & MEDIAN & 97.71 & 0.9761 \\
\hline BICUBIC & BILINEAR & MINIMUM & 98.22 & 0.9815 \\
\hline BICUBIC & BICUBIC & MAXIMUM & 97.46 & 0.9734 \\
\hline BICUBIC & BICUBIC & MEAN & $\mathbf{9 8 . 4 7}$ & 0.9842 \\
\hline BICUBIC & BICUBIC & MEDIAN & 97.71 & 0.9761 \\
\hline BICUBIC & BICUBIC & MINIMUM & 98.22 & 0.9815 \\
\hline
\end{tabular}

In this study, mean and bicubic techniques are acceptable for many data types.

Because of the coarse spatial resolution of the input maps, the output maps would lack detailed information and contained some mixed pixels (hard to separate into urban or non-urban classes). Besides, the training dataset and the testing dataset are not large enough to ensure objectiveness. Therefore, they might have unexpected effects on performance measures.

In the future, we will focus on studying better classification methods with higher-resolution input data to produce more exact and detailed urban maps. Specifically, we will utilize some machine learning methods, such as neural network, support vector machine, and ensemble methods on high-resolution data such as Landsat data, radar data, etc.

\section{ACKNOWLEDGMent}

The authors would like to thank the VNU QMT 17.03 research project "Building a system for collecting, processing multi-sources data to monitor urban-cover change and air pollution" for financial support. 


\section{REFERENCES}

[1] The World Bank, "Vietnam Urbanization Review: Technical Assistance Report," p. 263, 2011.

[2] B. Yuen and A. Kumssa, Climate Change and Sustainable Urban Development in Africa and Asia, 2010.

[3] P. T. Dung, M. D. Chuc, N. T. N. Thanh, B. Q. Hung, and D. M. Chung, "Optimizing GLCNMO version 2 method to detect Vietnam's urban expansion," in Proceedings of the Eighth International Conference on Knowledge and Systems Engineering (KSE), 2016, pp. 309-314.

[4] D. Drakakis-Smith and C. Dixon, "Sustainable urbanization in Vietnam," Geoforum, vol. 28, no. 1, pp. 21-38, 1997.

[5] T. T. Van, "Relationship Between Surface Temperature and Land Cover Types Using Thermal Infrared Remote Sensing, in Case of HoChiMinh City," in Proceedings of the Sixteenth Workshop of OMISAR on the Application of Satellite Data, 2005, pp. 1-4.

[6] T. T. An and V. A. Tuan, "Application of Remote Sensing in Land Use Change Pattern in Da Nang City , Vietnam," in Proceedings of the International Symposium on Geoinformatics for Spatial Infrastructure Development in Earth and Allied Sciences, 2008.

[7] T. D. B. Tran, A. Puissant, D. Badariotti, and C. Weber, "Optimizing spatial resolution of imagery for urban form detection-the cases of France and Vietnam," Remote Sensing, vol. 3, no. 10, pp. 2128-2147, 2011.

[8] H. M. Pham, Y. Yamaguchi, and T. Q. Bui, "A case study on the relation between city planning and urban growth using remote sensing and spatial metrics," Landscape and Urban Planning, vol. 100, no. 3, pp. 223-230, 2011.

[9] N. Hoang Khanh Linh and H. Van Chuong, "Assessing the impact of urbanization on urban climate by remote satellite perspective: a case study in Danang city, Vietnam," International Archives of the Photogrammetry, Remote Sensing \& Spatial Information Sciences, vol. XL-7/W3, no. May, pp. 207-212, 2015.

[10] R. Tateishi, B. Uriyangqai, H. Al-Bilbisi, M. A. Ghar, J. Tsend-Ayush, T. Kobayashi, A. Kasimu, N. T. Hoan, A. Shalaby, B. Alsaaideh, T. Enkhzaya, Gegentana, and H. P. Sato, "Production of global land cover data - GLCNMO," International Journal of Digital Earth, vol. 4, no. 1, pp. 2249, 2011

[11] D. X. Phong, N. T. Hoan, T. Kobayashi, R. Tateishi, and L. Cover, "A GLOBAL 500-M URBAN MAP FOR GLCNMO VERSION 2," no. Glcnmo 2003, 2012.

[12] B. Alsaaideh, R. Tateishi, D. X. Phong, N. T. Hoan, A. AlHanbali, and B. Xiulian, "New urban map of Eurasia using MODIS and multi-source geospatial data," Geo-spatial Information Science, vol. 20, no. 1, pp. 29-38, 2017.

[13] B. L. Markham and J. R. G. Townshend, "Land cover classification accuracy as a function of sensor spatial resolution," in Int. Symp. Remote Sens. Environ., Ann Arbor, 1981, pp. 1075-1090.

[14] H. Studley and K. T. Weber, "Comparison of Image Resampling Techniques for Satellite Imagery," Final Report: Assessing Post-Fire Recovery of Sagebrush-Steppe Rangelands in Southeastern Idaho, pp. 185-196, 2011.

[15] L. Bian and R. Butler, "Comparing effects of aggregation methods on statistical and spatial properties of simulated spatial data," Photogrammetric Engineering and Remote Sensing, vol. 65, no. 1, pp. 73-84, 1999.

[16] Z. X. Z. Xiuling, L. Z. L. Zhaoli, L. L. L. Lina, and W. H. W. Huisheng, "Evaluation of spatial aggregation methods based on satellite classification data," in Proceedings of the International Conference on Environmental Science and Information Application Technology (ESIAT), vol. 1, 2010, pp. 609-613.
[17] V. Patel and P. K. Mistree, "A Review on Different Image Interpolation Techniques for Image Enhancement," International Journal of Emerging Technology and Advanced Engineering, vol. 3, no. 12, pp. 129-133, 2013.

[18] J. Titus, M. T. S. Cse, and S. Geroge, "A Comparison Study On Different Interpolation Methods Based On Satellite Images," International Journal of Engineering Research \& Technology, vol. 2, no. 6, pp. 82-85, 2013.

[19] A. E. Gaughan, F. R. Stevens, C. Linard, P. Jia, and A. J. Tatem, "High Resolution Population Distribution Maps for Southeast Asia in 2010 and 2015," PLoS One, vol. 8, no. 2, p. e55882, feb 2013.

[20] Y. Xie, Q. Weng, and A. Weng, "A comparative study of NPP-VIIRS and DMSP-OLS nighttime light imagery for derivation of urban demographic metrics," in Proceedings of the 3rd International Workshop on Earth Observation and Remote Sensing Applications (EORSA), 2014, pp. 335-339.

[21] J. F. Knight, R. S. Lunetta, J. Ediriwickrema, and S. Khorram, "Regional Scale Land Cover Characterization Using MODIS-NDVI $250 \mathrm{~m}$ Multi-Temporal Imagery: A Phenology-Based Approach," GIScience \& Remote Sensing, vol. 43, no. 1, pp. 1-23, 2007.

[22] C. D. Elvidge, B. T. Tuttle, P. S. C. Sutton, K. E. Baugh, A. T. Howard, C. Milesi, B. L. Bhaduri, and R. Nemani, "Global Distribution and Density of Constructed Impervious Surfaces," Sensors, vol. 7, pp. 1962-1979, 2007.

[23] M. Carroll, J. Townshend, C. DiMiceli, P. Noojipady, and R. Sohlberg, "A new global raster water mask at $250 \mathrm{~m}$ resolution," International Journal of Digital Earth, vol. 2, no. 4, pp. 291-308, 2009.

[24] D. Li, J. Shan, and J. Gong, Geospatial Technology for Earth Observation Data (Google eBook), 2009, vol. 2009.

[25] R. Raj, N. a.S. Hamm, and Y. Kant, "Analysing the effect of different aggregation approaches on remotely sensed data," International Journal of Remote Sensing, vol. 34, no. 14, pp. 4900-4916, 2013.

[26] D. Poobathy and R. M. Chezian, "Edge Detection Operators: Peak Signal to Noise Ratio Based Comparison," I.J. Image, Graphics and Signal Processing, vol. 6, no. 10, pp. 55-61, 2014.

[27] V. Karathanassi, P. Kolokousis, and S. Ioannidou, A comparison study on fusion methods using evaluation indicators, 2007, vol. 28, no. 10 .

[28] Z. Wang, A. C. Bovik, H. R. Sheikh, and E. P. Simoncelli, "Image quality assessment: From error visibility to structural similarity," IEEE Transactions on Image Processing, vol. 13, no. 4, pp. 600-612, 2004.

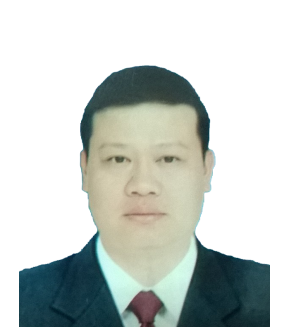

Pham Tuan Dung received his M.S. in Computer Science from the Posts and Telecommunications Institute of Technology (PTIT) in 2012. Currently, he is a Ph.D. candidate at the Faculty of Information Technology and a researcher at the Center of Multidisciplinary Integrated Technologies for Field Monitoring (FIMO Center), University of Engineering and Technology, Vietnam National University, Hanoi. His research interests include Remote Sensing Processing and Land Cover Classification. 


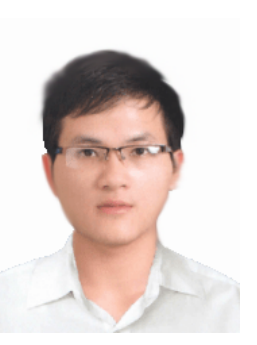

Man Duc Chuc received his B.S. and M.S. degrees in Information Technology from University of Engineering and Technology, Vietnam National University, Hanoi in 2014, and 2017, respectively. He is now a researcher at the Center of Multidisplinary Integrated Technologies for Field Monitoring (FIMO Center), University of Engineering and Technology, Vietnam National University, Hanoi. $\mathrm{He}$ is interested in Satellite Image Processing, Remote Sensing, and Lancover/Landuse Change Monitoring.

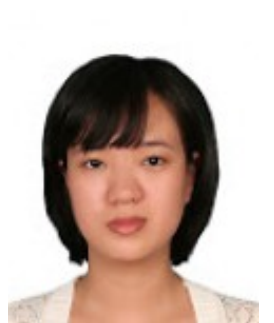

Nguyen Thi Nhat Thanh received B.S. and M.S. degrees in Information Technology from the University of Engineering and Technology, Vietnam National University, Hanoi in 2001 and 2005, respectively. She received a Ph.D. at University of Ferrara, Italy in 2012. Her research interests are in Atmospheric Data Measurement and Modeling, Remote Sensing, Pattern Recognition and Machine Learning, and Human Computer Interaction. She is now an associate professor and a researcher in University of Engineering and Technology, Vietnam National University.

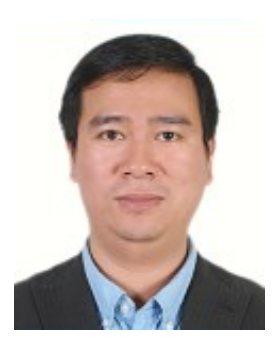

Bui Quang Hung got his M.S. and Ph.D. degrees in the field of System Innovation from Osaka University, Japan in 2005 and 2008, respectively. His research interests include Spatial Data Infrastructure, Spatial Data Mining, Spatial Database/Data Warehouse, and Field Monitoring. Currently, he is Director of the Center of Multidisciplinary Integrated Technologies for Field Monitoring (FIMO Center) at the University of Engineering and Technology, Vietnam National University, Hanoi.

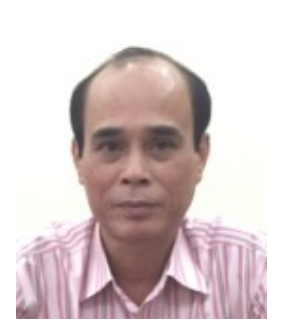

Doan Minh Chung is an associate professor at the Space Technology Institute (STI), Vietnam Academy of Science and Technology. He is serving as the Chairman of 2016-2020 National Space Science and Technology Program. As a researcher, he is interested in Remote Sensing and Microwave Radiometer Systems. 